\title{
Exploring the clinical association between neurological symptoms and COVID- 19 pandemic outbreak: A systematic review of current Literature
}

Davide Tiziano Di Carlo

University of Pisa https://orcid.org/0000-0001-7136-4408

Nicola Montemurro

University of Pisa

Giandomenico Petrella

University of Pisa

Gabriele

Siciliano

Roberto Ceravolo

University of Pisa

Paolo Perrini ( $\triangle$ paolo.perrini@unipi.it)

University of Pisa

\section{Systematic Review}

Keywords: COVID-19, SARS-CoV-2, coronavirus, $\beta$-coronavirus, neurological symptoms

Posted Date: May 7th, 2020

DOI: https://doi.org/10.21203/rs.3.rs-27152/v1

License: () (7) This work is licensed under a Creative Commons Attribution 4.0 International License. Read Full License

Version of Record: A version of this preprint was published at Journal of Neurology on August 1st, 2020. See the published version at https://doi.org/10.1007/s00415-020-09978-y. 


\section{Abstract}

Object: The novel severe acute respiratory syndrome (SARS)-CoV-2 outbreak has been declared a pandemic in March, 2020. An increasing body of evidence suggests that patients with the coronavirus disease (COVID-19) might have a heterogeneous spectrum of neurological symptoms

Methods. A systematic search of two databases was performed for studies published up to April $17^{\text {th }}, 2020$. PRISMA guidelines were followed.

Results: We included 13 studies evaluating 2499 patients with laboratory-confirmed COVID-19 infections. The median age of patients was 50.3 (IQR 9.6), and the rate of male patients was $50 \%(95 \% \mathrm{Cl} 47.9-52 \%)$. The most common reported comorbidities were hypertension and diabetes (18.7\%, $95 \% \mathrm{Cl} 16.9-20.7 \%$ and $9 \%, 95 \% \mathrm{Cl} 7.4-11.3 \%$, respectively). Headache was reported in $17.9 \%$ of patients (95\% $\mathrm{Cl} 16.1-19.8 \%)$, and dizziness in $13.9 \%$ (95\% $\mathrm{Cl} 10.7-18 \%$ ). Fatigue or myalgia, hypo/anosmia, and gustatory dysfunction were reported in $24 \%, 55.2 \%$, and $55.4 \%$, of patients, respectively.

Conclusions: These data support accumulating evidence that a significant proportion of patients with COVID-19 infection develop neurological manifestations, especially olfactory and gustatory dysfunction. The pathophysiology of this association is under investigation and warrants additional studies, Physicians should be aware of this possible association because during the epidemic period of COVID-19, early recognition of neurologic manifestations otherwise not explained would raise the suspect of acute respiratory syndrome coronavirus 2 infection.

\section{Introduction}

In December 2019, several cases of atypical pneumonia occurred in the Wuhan province in China, and then spread to rest of the country, then to Europe, North America, and Asia. The outbreak was confirmed to be caused by severe acute respiratory syndrome coronavirus 2 (SARS-CoV-2)[1]. This new coronavirus belongs to human $\beta$-coronaviruses, that also includes middle east respiratory syndrome (MERS)-CoV, and SARS-CoV-1. These viruses are mainly associated with respiratory-related diseases, such as pneumonia, ARDS, and pulmonary oedema[2-4]. In March 2020, the WHO declared the coronavirus disease 2019 (COVID-19) as an outbreak pandemic, and as of April $20^{\text {th }}$, more than 2 million people were confirmed positive, and there were more than 150.000 deaths globally[5]. According to the clinical investigations from Asia, common clinical manifestations include fever, cough, dyspnea, diarrhea, and fatigue associated with typical laboratory findings and lung abnormalities on a computed tomography (CT) scan[6]. Additionally, some patients with COVID-19 presented neurologic manifestations, such as headache, loss of sense of smell, stroke and seizures, suggesting that SARS-CoV-2, like MERS-CoV and SARS-CoV-1, displays neurotropism and enters the central nervous system $[7,8]$. The aim of this systematic review was to investigate the occurrence of different neurologic symptoms associated with COVID-19 and to assess their rate.

\section{Methods}

\section{Literature search}

A comprehensive literature search of two databases (PubMed and Ovid EMBASE) was conducted by an experienced librarian with input from the authors on April 17 1 th 2020 in accordance with PRISMA guidelines (Preferred Reporting Items for Systematic Reviews and Meta-Analysis)[9]. The key words and the detailed search strategy are reported in table 1. The inclusion criteria were the following: (1) series reporting patients with laboratory diagnosis of COVID-19 infection, and (2) cohort studies, case-controls studies, case series. Exclusion criteria were the following: (1) review articles, (2) studies published in languages other than English with no available English translations, (3) studies with overlapping patient population, and (4) studies with no neurological evaluation. In cases of overlapping patient populations, only the series with the largest number of patients or most detailed data were included. Two independent readers (D.D.C. and G.P.) screened articles in their entirety to determine eligibility for inclusion. Senior author solved discrepancies (P.P.).

\section{Data collection}

From each study, we extracted the following: (1) demographic data, (2) patients' comorbidity, and (3) clinical symptoms at presentation. Symptoms including emesis, nausea, diarrhea, and abdominal pain were collected as "digestive symptoms". Neurological symptoms were categorized into three categories, as follows: central nervous system (CNS) manifestations (dizziness, headache, impaired consciousness, acute cerebrovascular disease, ataxia, and seizures), peripheral nervous system (PNS) manifestations (taste impairment and smell impairment), and muscular injury manifestations (myalgia, muscular pain, fatigue)[7]. Data were obtained for the whole population and subsequently we divided it into two groups: severe patients and non-severe patients, according to the American Thoracic Society guidelines for community-acquired pneumonia[10]

\section{Outcomes}

The primary objective of this systematic review was to analyze the overall rate of neurologic symptoms among COVID-19 patients. Secondary objective was to compare the results between patients with severe and non-severe infection.

\section{Quality scoring}

A modified version of the Newcastle-Ottawa Scale[11] was used for the quality assessment of the included studies. The quality assessment was performed by 2 authors independently, and the senior author solved discrepancies.

\section{Statistical analysis}


Inter-observer agreement was tested with Cohen's kappa coefficient (k). The Wald method was used to calculate confidence intervals for event rates. Fisher's exact test was used for categorical variables. Statistical analyses were performed with SPSS version 23 (SPSS Inc. SPSS ${ }^{\circ}$ Chicago, IL, USA).

\section{Results}

\section{Literature review}

Studies included in our systematic review are summarized in table 2. Intra-observer agreement was 0.78 . The search flow diagram is shown in figure 1. Thirteen studies[4, 7, 19-21, 8, 12-18] and 2499 patients with laboratory-confirmed COVID-19 infection were included in our study.

\section{Quality of studies}

There was complete agreement between the two reviewers for the examined articles. Seven studies were retrospective single-center designed, whereas four studies were multicentric investigations. All 11 papers were rated as "high quality" (table 3). Two publications were letters to the editor. Accordingly, they were rated as "low quality" evidence, due to the type of the publication.

\section{Demographic data and clinical characteristics}

Overall, the median age of patients was 50.3 (IQR 9.6), and the proportion of male patients was $50 \%$ (95\% $\mathrm{Cl} 47.9-52 \%)$. Hypertension was the most common comorbidity $(18.7 \%, 95 \% \mathrm{Cl} 16.9-20.7 \%)$ among our population, whereas fever was the most common clinical presentation $(77.1 \%, 95 \% \mathrm{Cl} 75.4-78.7 \%)$. Detailed data and $\mathrm{Cl}$ are reported in table 4 . When considering the severity of the disease, the two sub-groups were not homogeneous in terms of comorbidity in our analysis. Indeed, patients with a history of hypertension, cardiovascular disease, diabetes, and concurrent malignancy were significantly more common in the "severe" subgroup $(p<0.01)$ (table 5).

\section{Neurological symptoms}

Among CNS symptoms, headache was reported in 10 studies and in $17.9 \%$ of patients ( $95 \% \mathrm{Cl} 16.1-19.8 \%)$. Dizziness was observed in $13.9 \%$ of patients in two different series (95\% Cl 10.7-18\%). Myalgia was reported in 372 of 1361 patients $(23.1 \%, 95 \% 21.1-25.2 \%)$ in 5 studies, and fatigue occurred in 179 of 757 patients $(27.3 \%, 95 \% \mathrm{Cl} 20.1-26.8 \%)$ in 4 series. Among these studies, only one paper (Wang et al.) reported both symptoms. On the other hand, Mao et al., Wan et al. and $\mathrm{Xu}$ et al. reported the overall rate of fatigue/myalgia as a single data. Accordingly, we decided to gather data obtaining an overall rate of $24.4 \%$ (95\% $\mathrm{Cl} 22.6-26.2 \%)$ of patients presenting myalgia or fatigue at clinical admission. The most common neurological symptom was the impairment of olfactory and gustatory functions $(54.2 \%, 95 \% \mathrm{Cl} 50.5-57.9 \%$ and $55.4 \%, 95 \% \mathrm{Cl} 51.6-59 \%$, respectively). Interestingly, both CNS symptoms and muscular injury manifestations were more common among severe patients (dizziness: $20.1 \%$ vs $10.5 \%, p=0.02$; headache: $13 \%$ vs $8 \%$, $p=0.01$; skeletal muscle injury: $29.4 \%$ vs $11.8 \%, p<0.01)$. The rate of PNS were compared between severe and non-severe populations only in one study, and no significant difference arose from the analysis (table 5).

\section{Discussion}

Limited reports described neurologic complications of SARS-CoV-1 and MERS-CoV, mainly restricted to axonal peripheral neuropathy, acute disseminated encephalomyelitis, and stroke[22, 23]. Our systematic review of 2499 patients reported the occurrence of a wide spectrum of neurologic complications in hospitalized patients with laboratory-confirmed COVID-19 infection, supporting the possible neuroinvasive potential of SARS-CoV-2.

\section{The potential neurotropism of SARS-CoV-2}

A growing body of evidence suggests that SARS-CoV-2, similarly to SARS-CoV-1, has neuroinvasive potential, possibly through the retrograde neuronal route[24, 25]. Recent studies reported that the expression level of angiotensin converting enzyme 2 (ACE2) is critical for the susceptibility of SARS-CoV-1 and SARS-CoV-2 infection[26]. The cellular receptor ACE2 is expressed in different tissues and organs including the nervous system and skeletal muscles[27]. Autopsy samples from patients with SARS clearly demonstrated the presence of SARS-CoV-1 in brain samples[28, 29]. Interestingly, laboratory investigations on transgenic mice for the SARS-CoV receptor (ACE2) demonstrated that the virus enters the brain via the olfactory bulb with resultant rapid transneuronal spread to different brain regions including cortical areas (piriform and infralimbic cortices), basal ganglia (ventral pallidum and lateral preoptic regions), and midbrain (dorsal raphe). In these regions, a significant neuronal death occurs[30]. A recent report confirmed the presence of SARS-CoV-2 in cerebrospinal fluid by genome sequencing in a patient with viral encephalitis, confirming the neurotropism of SARS-CoV2[31, 32]. They proposed that the respiratory failure in patients with COVID-19 is related to the neuronal loss at the level of the cardiorespiratory center in the brainstem. However, type 1 respiratory failure with low CO2 levels and raised respiratory rate observed in patients with COVD-19 is more likely related to pneumonia instead of brainstem dysfunction that leads to failure of breathing associated with reduced respiratory rate and high $\mathrm{C} 02$ levels (type 2 respiratory failure)[33].

Symptoms related to skeletal muscle injury are generally associated with elevated creatine kinase and lactate dehydrogenase levels. It was initially suspected that this injury was related to the presence of ACE-2 in skeletal muscle[34]. However, immunohistochemistry and in situ hybridization failed to detect SARS$\mathrm{CoV}$ in the skeletal muscle of patients who died of SARS, suggesting a putative role of a systemic inflammatory response syndrome (SIRS) in the pathogenesis of muscular damage[28]. It is supposed that SIRS can occur in pneumonia caused by COVID-19 infection and promotes multiple organ failures in patients with severe infection. Further clinical and laboratory investigations are required to clarify the neurotropism of SARS-COV-2 and its neuroinvasive potential.

\section{Neurologic Manifestations of SARS-CoV-2 Infection}


Neurologic manifestations in patients with COVID-19 are common. In a recent retrospective study, Mao et al. reported nervous system-related clinical findings in 78 of 214 hospitalized patients (36.4\%) and categorized neurological disturbances into three groups: CNS manifestations, PNS manifestations, and skeletal muscular injury manifestations. Interestingly, their report suggested that patients with severe infection were more likely to develop CNS and muscular injury symptoms[7]. The results of our analysis are consistent with their findings, demonstrating a significant difference among severe and non-severe patients. Nonetheless, the two groups were not homogeneous in terms of clinical comorbidity, and severe patients were characterized by a significant higher rate of concomitant hypertension, cardiovascular disease, malignancy, and diabetes. Accordingly, as previously discussed, a direct link between the occurrence of neurological symptoms and the clinical condition cannot be drawn at the current state of knowledge. However, the occurrence of multiorgan damage in patients with muscle injury suggests that infection-mediated immune response probably plays a role as a causative factor of skeletal muscle damage. In fact, these patients present not only significantly higher levels of creatine kinase but also higher neutrophil counts, lower lymphocyte counts, higher C-reactive protein levels, and higher D-dimer levels indicating increased inflammatory response and coagulation activation[7, 24]. Similar findings were reported in patients with MERS and SARS-CoV-1 infection[35, 36]. Our study demonstrated that olfactory and gustatory function impairment were the most common neurologic manifestations in patients with COVD-19 and were detected in more than $50 \%$ of patients. Lechien et al. extensively examined this topic in a multicentric investigation and reported an overall rate of olfactory and gustatory dysfunctions of roughly 85 and $88 \%$, respectively[15]. In this study, olfactory and gustatory dysfunction were both prevalent in patients with mild-to-moderate COVID-19 infection and hyposmia was generally observed in patients without nasal obstruction or rhinorrhea before, during or after the general symptoms. It is worth noting that the prevalence of olfactory and gustatory dysfunction was substantially higher in European cohorts compared with the Asian cohorts $[4,15]$. This difference is poorly understood and requires further investigation. Scant information is available on MRI investigations of the brain in patients with COVID-19. In the series of Helms at al., an MRI was performed in 13 patients because of encephalopathic features and demonstrated two asymptomatic acute ischemic strokes and one subacute ischemic stroke[8].

\section{Limitations of the study}

Our study has limitations. The series are often small, retrospective, and single-institution experiences. Furthermore, due to the contemporaneity of the outbreak, the follow-up is short, and the occurrence of late onset neurological deficits cannot be analyzed. Furthermore, only two studies[7, 8] have analyzed, as primary outcome, the neurological characteristics of their patients. In addition, advanced neuroimaging (MRI) and diagnostic procedures (lumbar puncture, electromyography/nerve conduction velocity) were rarely reported in the studies included. However, our review is the largest study to date that provides a representation of data concerning neurological symptoms among laboratory-confirmed COVID-19 population.

\section{Conclusions}

Accumulating evidence suggests that a significant proportion of patients with COVID-19 infection develops neurological manifestations, especially olfactory and gustatory dysfunction. The pathophysiology of this association is under investigation and warrants additional studies. Physicians should be aware of this possible association because during the epidemic period of COVID-19, early recognition of neurologic manifestations otherwise not explained should raise the suspect of acute respiratory syndrome coronavirus 2 infection.

\section{Declarations}

\section{Funding}

No funding was received for this research.

\section{Disclosure of potential conflicts of interest}

All authors certify that they have no affiliations with or involvement in any organization or entity with any financial interest (such as honoraria; educational grants; participation in speakers' bureaus; membership, employment, consultancies, stock ownership, or other equity interest; and expert testimony or patentlicensing arrangements), or non-financial interest (such as personal or professional relationships, affiliations, knowledge or beliefs) in the subject matter or materials discussed in this manuscript.

\section{Research involving Human Participants and/or Animals}

This article does not contain any studies with human participants or animals performed by any of the authors

\section{Ethical approval}

For this type of study formal consent is not required

\section{Informed consent}

The nature of this article did not require informed consent

\section{References}

1. Lu H, Stratton CW, Tang Y Outbreak of Pneumonia of Unknown Etiology in Wuhan China: the Mystery and the Miracle. J Med Virol

2. Assiri A, Al-Tawfiq JA, Al-Rabeeah AA, et al (2013) Epidemiological, demographic, and clinical characteristics of 47 cases of Middle East respiratory syndrome coronavirus disease from Saudi Arabia: a descriptive study. Lancet Infect Dis 13:752-761 
3. Peiris JSM, Lai ST, Poon LLM, et al (2003) Coronavirus as a possible cause of severe acute respiratory syndrome. Lancet 361:1319-1325

4. Chen N, Zhou M, Dong X, et al (2020) Epidemiological and clinical characteristics of 99 cases of 2019 novel coronavirus pneumonia in Wuhan, China: a descriptive study. Lancet. https://doi.org/10.1016/S0140-6736(20)30211-7

5. World Health Organization. Coronavirus disease 2019 (COVID-19) situation report. Accessed April 20, 2020

6. Huang C, Wang Y, Li X, et al (2020) Clinical features of patients infected with 2019 novel coronavirus in Wuhan, China. Lancet 395:497-506

7. Mao L, Jin H, Wang M, et al (2020) Neurologic Manifestations of Hospitalized Patients With Coronavirus Disease 2019 in Wuhan, China. JAMA Neurol. https://doi.org/10.1001/jamaneurol.2020.1127

8. Helms J, Kremer S, Merdji H, et al (2020) Neurologic Features in Severe SARS-CoV-2 Infection. N. Engl. J. Med.

9. Moher D, Liberati A, Tetzlaff J, et al (2009) Preferred Reporting Items for Systematic Reviews and Meta-Analyses: The PRISMA Statement (Reprinted from Annals of Internal Medicine). Phys Ther 89:873-880. https://doi.org/10.1371/journal.pmed.1000097

10. Metlay JP, Waterer GW, Long AC, et al (2019) Diagnosis and treatment of adults with community-acquired pneumonia. An official clinical practice guideline of the American Thoracic Society and Infectious Diseases Society of America. Am J Respir Crit Care Med 200:e45-e67

11. Wells GA, Shea B, O'Connell D, et al (2013) The Newcastle-Ottawa Scale (NOS) for assessing the quality of nonrandomized studies in meta-analyses. Ottawa Hosp Res Inst 1-4. https://doi.org/10.2307/632432

12. Cai Q, Huang D, Ou P, et al (2020) COVID-19 in a Designated Infectious Diseases Hospital Outside Hubei Province, China. Allergy. https://doi.org/10.1111/all.14309

13. Feng Y, Ling Y, Bai T, et al (2020) COVID-19 with Different Severity: A Multi-center Study of Clinical Features. Am J Respir Crit Care Med. https://doi.org/10.1164/rccm.202002-04450C

14. Giacomelli A, Pezzati L, Conti F, et al (2020) Self-reported olfactory and taste disorders in SARS-CoV-2 patients: a cross-sectional study. Clin Infect Dis. https://doi.org/10.1093/cid/ciaa330 LK - http://onesearch.unifi.it/openurl/39UFI/39UFI_Services?

\&sid=EMBASE\&issn=15376591\&id=doi:10.1093\%2Fcid\%2Fciaa330\&atitle=Self-reported+olfactory+and+taste+disorders+in+SARS-CoV-

$2+$ patients $\% 3 A+a+c r o s s-$

sectional+study\&stitle=Clin.+Infect.+Dis.\&title=Clinical+infectious+diseases+\%3A+an+official+publication+of+the+Infectious+Diseases+Society+of+Amer \&date $=2020$ \&aui

15. Lechien JR, Chiesa-Estomba CM, De Siati DR, et al (2020) Olfactory and gustatory dysfunctions as a clinical presentation of mild-to-moderate forms of the coronavirus disease (COVID-19): a multicenter European study. Eur Arch Otorhinolaryngol. https://doi.org/10.1007/s00405-020-05965-1

16. Li K, Wu J, Wu F, et al (2020) The Clinical and Chest CT Features Associated with Severe and Critical COVID-19 Pneumonia. Invest Radiol. https://doi.org/10.1097/RLI.0000000000000672

17. Li R, Tian J, Yang F, et al (2020) Clinical characteristics of 225 patients with COVID-19 in a tertiary Hospital near Wuhan, China. J Clin Virol 127:104363. https://doi.org/10.1016/j.jcv.2020.104363 LK - http://onesearch.unifi.it/openurl/39UFl/39UFI_Services?

\&sid=EMBASE\&issn=18735967\&id=doi:10.1016\%2Fj.jcv.2020.104363\&atitle=Clinical+characteristics+of+225+patients+with+COVID-

$19+$ in $+a+$ tertiary+Hospital+near+Wuhan $\% 2 C+C h i n a \& s t i t l e=J .+C l i n .+V i r o l . \&$ title $=$ Journal + of + Clinical+Virology \&volume $=127 \& i s s u e=\& s p a g e=\& e p a g e=\& a u l a$ \&date=2020\&auinit $1=\mathrm{R} \&$ auinitm $=$

18. Tian S, Hu N, Lou J, et al (2020) Characteristics of COVID-19 infection in Beijing. J Infect 80:401-406. https://doi.org/10.1016/j.jinf.2020.02.018 LK http://onesearch.unifi.it/openurl/39UFI/39UFI_Services?

\&sid=EMBASE\&issn=15322742\&id=doi:10.1016\%2Fj.jinf.2020.02.018\&atitle=Characteristics+of+COVID-

$19+$ +infection+in+Beijing\&stitle=J.+Infect.\&title=Journal+of+Infection\&volume=80\&issue=4\&spage=401\&epage=406\&aulast=Tian\&aufirst=Sijia\&auinit=S. $\varepsilon$ 406\&date $=2020 \&$ auinit $1=$ S\&auinitm $=$

19. Wan S, Xiang Y, Fang W, et al (2020) Clinical features and treatment of COVID-19 patients in northeast Chongqing. J Med Virol. https://doi.org/10.1002/jmv.25783

20. Wang D, Hu B, Hu C, et al (2020) Clinical Characteristics of 138 Hospitalized Patients With 2019 Novel Coronavirus-Infected Pneumonia in Wuhan, China. JAMA 323:1061-1069. https://doi.org/10.1001/jama.2020.1585

21. Xu X-W, Wu X-X, Jiang X-G, et al (2020) Clinical findings in a group of patients infected with the 2019 novel coronavirus (SARS-Cov-2) outside of Wuhan, China: retrospective case series. BMJ 368:m606. https://doi.org/10.1136/bmj.m606

22. Desforges M, Favreau DJ, Brison É, et al (2013) Human Coronaviruses: Respiratory pathogens revisited as infectious neuroinvasive, neurotropic, and neurovirulent agents

23. Arabi YM, Balkhy HH, Hayden FG, et al (2017) Middle East respiratory syndrome. N Engl J Med 376:584-594

24. Wu Y, Xu X, Chen Z, et al (2020) Nervous system involvement after infection with COVID-19 and other coronaviruses. Brain Behav Immun. https://doi.org/10.1016/j.bbi.2020.03.031

25. Li Y-C, Bai W-Z, Hashikawa T (2020) The neuroinvasive potential of SARS-CoV2 may play a role in the respiratory failure of COVID-19 patients. J Med Virol. https://doi.org/10.1002/jmv.25728

26. Li W, Zhang C, Sui J, et al (2005) Receptor and viral determinants of SARS-coronavirus adaptation to human ACE2. EMBO J 24:1634-1643

27. Lavoie JL, Sigmund CD (2003) Minireview: overview of the renin-angiotensin system-an endocrine and paracrine system. Endocrinology 144:2179-2183

28. Ding Y, He L, Zhang Q, et al (2004) Organ distribution of severe acute respiratory syndrome (SARS) associated coronavirus (SARS-CoV) in SARS patients: implications for pathogenesis and virus transmission pathways. J Pathol A J Pathol Soc Gt Britain Irel 203:622-630

29. Gu J, Gong E, Zhang B, et al (2005) Multiple organ infection and the pathogenesis of SARS. J Exp Med 202:415-424

Page 5/8 
30. Netland J, Meyerholz DK, Moore S, et al (2008) Severe Acute Respiratory Syndrome Coronavirus Infection Causes Neuronal Death in the Absence of Encephalitis in Mice Transgenic for Human ACE2. J Virol. https://doi.org/10.1128/jvi.00737-08

31. Xiang P, Xu XM, Gao LL, et al (2020) First case of 2019 novel coronavirus disease with Encephalitis. ChinaXiv 202003:15

32. Li Y-C, Bai W-Z, Hashikawa T (2020) The neuroinvasive potential of SARS-CoV2 may be at least partially responsible for the respiratory failure of COVID19 patients. J Med Virol. https://doi.org/10.1002/jmv.25728 LK - http://onesearch.unifi.it/openurl/39UFI/39UFI_Services?

\&sid=EMBASE\&issn=10969071\&id=doi:10.1002\%2Fjmv.25728\&atitle=The+neuroinvasive+potential+of +SARS-

CoV2+may+be+at+least+partially+responsible+for+the+respiratory+failure+of+COVID-

19+patients\&stitle=J.+Med.+Virol.\&title=Journal+of+Medical+Virology\&volume=\&issue=\&spage=\&epage=\&aulast=Li\&aufirst=Yan-Chao\&auinit=Y.-

C.\&aufull=Li+Y.-C.\&coden=JMVID\&isbn=\&pages=-\&date=2020\&auinit $1=$ Y\&auinitm $=-C$

33. Turtle L (2020) Respiratory failure alone does not suggest central nervous system invasion by SARS-CoV-2. J Med Virol

34. Cabello-Verrugio C, Morales MG, Rivera JC, et al (2015) Renin-angiotensin system: an old player with novel functions in skeletal muscle. Med Res Rev 35:437-463

35. Mahallawi WH, Khabour OF, Zhang Q, et al (2018) MERS-CoV infection in humans is associated with a pro-inflammatory Th1 and Th17 cytokine profile. Cytokine 104:8-13

36. He L, Ding Y, Zhang Q, et al (2006) Expression of elevated levels of pro-inflammatory cytokines in SARS-CoV-infected ACE2+ cells in SARS patients: relation to the acute lung injury and pathogenesis of SARS. J Pathol A J Pathol Soc Gt Britain Irel 210:288-297

\section{Tables}

\section{Table $1 \quad$ Search syntax}

PubMed search accessed on

April $17^{\text {th }}, 2020$

(263 articles)

((SARS-CoV-2[Title] OR 2019-nCov[Title] OR COVID-19[Title])) AND (neurological OR neurologic OR clinical characteristics )
Embase search accessed on April $17^{\text {th }}, 2020$

(154 articles)

('sars cov 2':ti OR '2019 ncov':ti OR 'covid 19':ti) AND (neurological OR neurologic OR 'clinical characteristics' OR (('clinical'/exp OR clinical) AND characteristics))

Table 2 Summary of the included studies

\begin{tabular}{|c|c|c|c|c|c|c|}
\hline Study & Journal & Hospital & Location & Period of recruitment (2020) & $\mathrm{N}$ patients & Age (median) \\
\hline Cai et al. ${ }^{12}$ & Allergy & People's Hospital of Shenzhen & Shenzhen City, China & January 11-February 6 & 298 & 47,5 \\
\hline Chen et al. ${ }^{4}$ & The Lancet & Jinyintan Hospital & Wuhan, China & January 1 -January 20 & 99 & $55,5^{\mathrm{a}}$ \\
\hline Feng et al. ${ }^{13}$ & AJRCCM & Multicentric & China & February 1-February 15 & 476 & 53 \\
\hline Giacomelli et al. ${ }^{14}$ & Clinic Infectious Disease & L. Sacco Hospital & Milan, Italy & NA & 59 & 60 \\
\hline Helms et al. ${ }^{8}$ & NEJM & Strasbourg University Hospital & Strasbourg, France & March 3-April 3 & 58 & 63 \\
\hline Lechien et al. ${ }^{15}$ & Rhinology & Multicentric & France-Italy & NA & 417 & $36,9^{\mathrm{a}}$ \\
\hline Li K et al. ${ }^{16}$ & Invest Radiol & Chongqing Medical University & Chongqing, China & January NA - February NA & 83 & $45,5^{\mathrm{a}}$ \\
\hline Li R et al. ${ }^{17}$ & Journal of Clinical Virology & Hanchuan City People's Hospital & Hanchuan, Cina & January 20-February 14, & 225 & $50 a$ \\
\hline Mao et al. ${ }^{7}$ & JAMA neurolgy & Multicentric & Wuhan, China & January 16-February 19 & 214 & $52,7^{\mathrm{a}}$ \\
\hline Tian et al. ${ }^{18}$ & Journal of Infection & Beijing Emergency Medical Service & Bejing, China & January 20-February 10 & 262 & 47,5 \\
\hline Wan et al. ${ }^{19}$ & Journal of Medical Virology & Three Georges Central Hospital & Chongqing, China & January 23-February 8 & 135 & 47 \\
\hline Wang et al. ${ }^{20}$ & JAMA & ZhongnanHospital ofWuhan University & Wuhan, China & January 1-February 28 & 138 & 56 \\
\hline $\mathrm{Xu}$ et al. $^{21}$ & TheBMJ & Multicentric & Zhejiang, China & January 10-January 26 & 35 & 41 \\
\hline
\end{tabular}

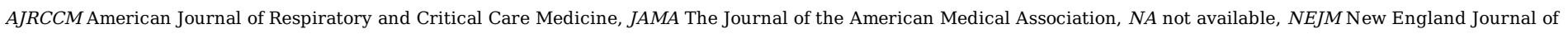
Medicine

a. Value expressed as mean

Table 3 Quality measure of included studies by the Newcastle-Ottawa quality assessment scale

\begin{tabular}{|c|c|c|c|c|c|c|c|c|c|c|}
\hline \multirow[t]{2}{*}{ Study } & \multicolumn{4}{|c|}{ Selection } & \multicolumn{2}{|c|}{ Comparabilty } & \multicolumn{3}{|c|}{ Outcome } & \multirow[t]{2}{*}{ Tot } \\
\hline & 1) & 2) & 3) & 4) & a) & b) & 1) & 2) & 3) & \\
\hline Mao et al. & $*$ & $*$ & $*$ & & $*$ & $*$ & $*$ & $*$ & & 7 \\
\hline $\mathrm{Xu}$ et al. & $*$ & $*$ & $*$ & & $*$ & $*$ & $*$ & $*$ & & 7 \\
\hline Wang et al. & $*$ & $*$ & $*$ & & $*$ & $*$ & $*$ & $*$ & & 7 \\
\hline Tian et al. & $*$ & $*$ & $*$ & & $*$ & $*$ & $*$ & $*$ & & 7 \\
\hline Yang et al. & $*$ & $*$ & $*$ & & $*$ & $*$ & $*$ & $*$ & & 7 \\
\hline Cai et al. & $*$ & $*$ & $*$ & & $*$ & $*$ & $*$ & $*$ & & 7 \\
\hline Chen et al. & $*$ & $*$ & $*$ & & $*$ & $*$ & $*$ & $*$ & & 7 \\
\hline Feng et al. & $*$ & $*$ & $*$ & & $*$ & $*$ & $*$ & $*$ & & 7 \\
\hline Li K et al. & $*$ & $*$ & $*$ & & $*$ & $*$ & $*$ & $*$ & & 7 \\
\hline Li R et al. & $*$ & $*$ & $*$ & & $*$ & $*$ & $*$ & $*$ & & 7 \\
\hline Lechien et al. & $*$ & $*$ & $*$ & & $*$ & $*$ & $*$ & $*$ & & 7 \\
\hline Wan et al. & $*$ & $*$ & $*$ & & $*$ & $*$ & $*$ & $*$ & & 7 \\
\hline
\end{tabular}




\begin{tabular}{|c|c|c|c|}
\hline & Raw data & Rate $(95 \% \mathrm{CI})$ & $\mathbf{N}$ of articles \\
\hline \multicolumn{4}{|l|}{ Demographic data } \\
\hline $\mathrm{N}$ patients included in the analysis & 2499 & & 13 \\
\hline Male patients & $1202 / 2406$ & $50 \%(47.9-52 \%)$ & 11 \\
\hline Age (median, IQR) & $50.3(9.6)$ & - & 8 \\
\hline \multicolumn{4}{|l|}{ Comorbidity } \\
\hline Hypertension & $211 / 1128$ & $18.7 \%(16.9-20.7 \%)$ & 7 \\
\hline Diabetes & $79 / 864$ & $9 \%(7.4-11.3 \%)$ & 6 \\
\hline Cardiovascular disease & $108 / 967$ & $11.2 \%(9.3-13.3 \%)$ & 6 \\
\hline Malignancy & $28 / 586$ & $4.8 \%(3.3-6.8 \%)$ & 4 \\
\hline Smoking & $109 / 1028$ & $10.6 \%(8.9-12.3 \%)$ & 3 \\
\hline \multicolumn{4}{|l|}{ Neurological symptoms } \\
\hline \multicolumn{4}{|l|}{ CNS } \\
\hline Dizziness & $49 / 352$ & $13.9 \%(10.7-18 \%)$ & 2 \\
\hline Headache & $287 / 1605$ & $17.9 \%(16.1-19.8 \%)$ & 10 \\
\hline \multicolumn{4}{|l|}{ PNS } \\
\hline Hypo/anosmia & $374 / 690$ & $54.2 \%(50.5-57.9 \%)$ & 3 \\
\hline Gustatory disorders & $382 / 690$ & $55.4 \%(51.6-59 \%)$ & 3 \\
\hline \multicolumn{4}{|l|}{ Muscular injury manifestation } \\
\hline Fatigue or myalgia & $506 / 2078$ & $24.4 \%(22.6-26.24 \%)$ & 10 \\
\hline \multicolumn{4}{|l|}{ Other symptoms } \\
\hline Fever & $1882 / 2441$ & $77.1 \%(75.4-78.7 \%)$ & 12 \\
\hline Cough & $1458 / 2441$ & $59.7 \%(57.8-61.7 \%)$ & 12 \\
\hline Dyspnea & $137 / 1001$ & $13.7 \%(11.7-16 \%)$ & 7 \\
\hline Pharyngodynia & $124 / 1502$ & $8.3 \%(7-9.8 \%)$ & 7 \\
\hline Digestive symptoms & $357 / 1320$ & $27.1 \%(24.7-29.5 \%)$ & 10 \\
\hline
\end{tabular}

CNS central nervous system, IQR inter-quartile range, $P N S$ peripheral nervous system

Table 5 Comparison of neurological symptoms among clinical severity subgroups

\begin{tabular}{|c|c|c|c|c|c|c|}
\hline & Nonsevere & $95 \%$ CI & Severe & $95 \% \mathrm{CI}$ & $\mathrm{P}$-value & N. Studies \\
\hline \multicolumn{7}{|l|}{ Comorbidity } \\
\hline Hypertension & $151 / 973$ & $15.5 \%(13.4-17.9 \%)$ & $121 / 371$ & $32.6 \%(28-37.6 \%)$ & $<0.01$ & 6 \\
\hline Cardiovascular disease & $41 / 1127$ & $3.6 \%(2.7-4.9 \%)$ & $40 / 465$ & $8.6 \%(3.4-11.5 \%)$ & $<0.01$ & 5 \\
\hline Diabetes & $66 / 973$ & $6.8 \%(5.4-8.6 \%)$ & $64 / 371$ & $17.3 \%(13.7-21.4 \%)$ & $<0.01$ & 6 \\
\hline Malignancy & $19 / 915$ & $2 \%(1.3-3.2 \%)$ & $24 / 346$ & $6.9 \%(4.7-10.2 \%)$ & $<0.01$ & 5 \\
\hline Smoking & $35 / 447$ & $7.8 \%(5.7-10.7 \%)$ & $18 / 164$ & $11 \%(7-16.8 \%)$ & 0.26 & 2 \\
\hline \multicolumn{7}{|l|}{ Neurological symptoms } \\
\hline \multicolumn{7}{|l|}{ CNS } \\
\hline Dizziness & $24 / 228$ & $10.5 \%(7.2-15.2 \%)$ & $25 / 124$ & $20.1 \%(14-28.1 \%)$ & 0.02 & 2 \\
\hline Headache & $67 / 837$ & $8 \%(6.3-10 \%)$ & $40 / 308$ & $13 \%(9.7-17.2 \%)$ & 0.01 & 6 \\
\hline PNS & & & & & & \\
\hline
\end{tabular}




\begin{tabular}{|c|c|c|c|c|c|c|}
\hline Hypo/anosmia & $8 / 126$ & $6.4 \%(3.1-11 \%)$ & $3 / 88$ & $3.4 \%(0.7-9 \%)$ & 0.5 & 1 \\
\hline Gustatory disorders & $9 / 126$ & $7.1 \%(36.4-13.2 \%)$ & $3 / 88$ & $3.4 \%(0.7-9 \%)$ & 0.7 & 1 \\
\hline \multicolumn{7}{|c|}{ Muscular injury manifestation } \\
\hline Myalgia or fatigue & $140 / 1189$ & $11.8 \%(10.1-13.7 \%)$ & $127 / 432$ & $29.4 \%(25.3-33.9 \%)$ & $<0.01$ & 7 \\
\hline
\end{tabular}

CNS central nervous system, PNS peripheral nervous system

\section{Figures}

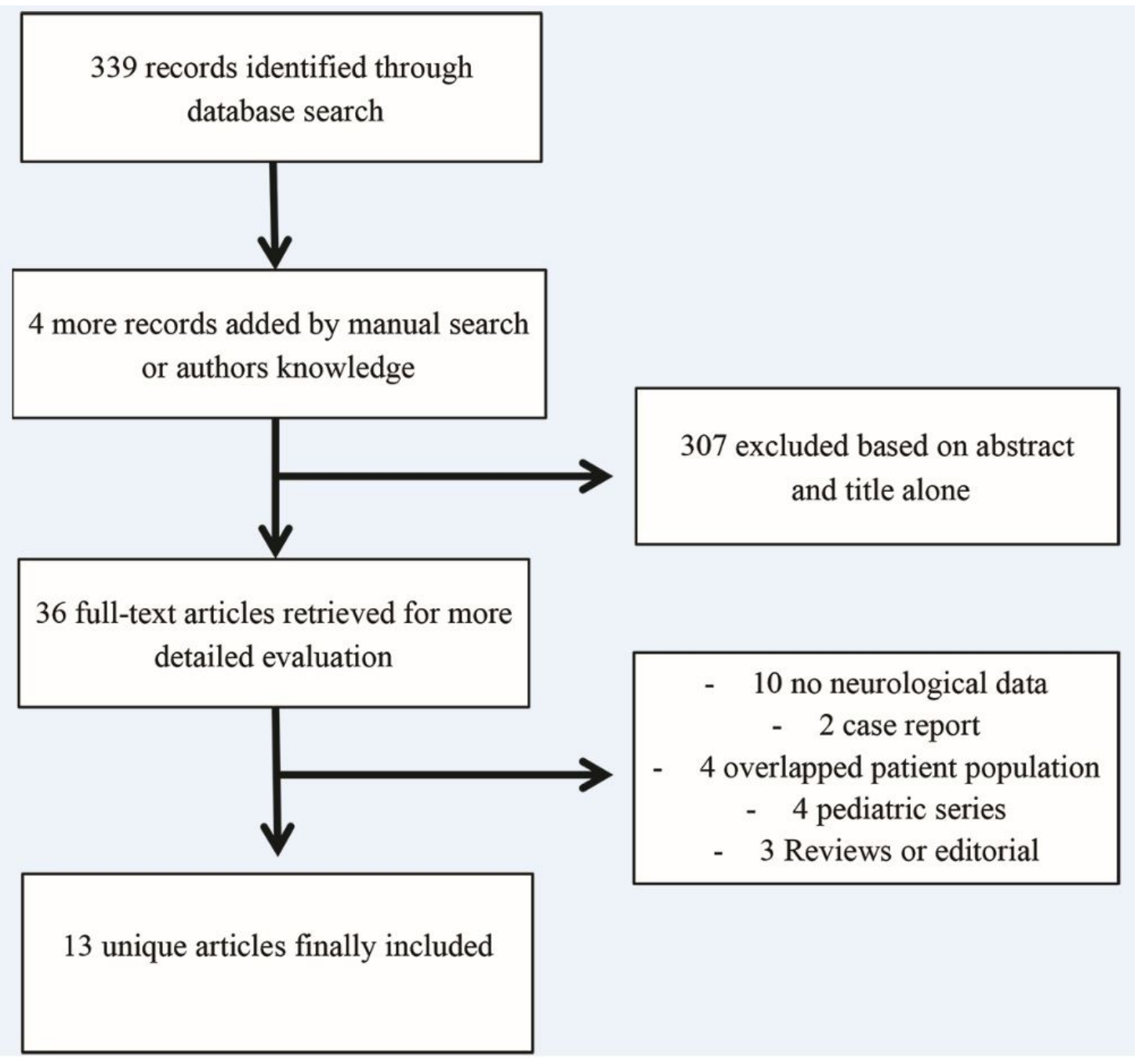

Figure 1

PRISMA diagram detailing the specifics of the systematic literature review 